\section{SCIENCE CHINA \\ Physics, Mechanics \& Astronomy}

-News \& Views•

January 2021 Vol. 64 No. 1: 217331

https://doi.org/10.1007/s11433-020-1596-5

\title{
Overcoming the limitations of gallium oxide through heterogeneous integration
}

\author{
Yuhao Zhang ${ }^{1 *}$, and Kevin J. Chen ${ }^{2}$ \\ ${ }^{1}$ Center for Power Electronics Systems, Virginia Polytechnic and State University, Blacksburg VA 24060, USA; \\ ${ }^{2}$ Departmnet of Electronic and Computer Engineering, The Hong Kong University of Science and Technology Hong Kong, China
}

Received May 19, 2020; accepted June 22, 2020; published online August 21, 2020

Citation: Y. Zhang, and K. J. Chen, Overcoming the limitations of gallium oxide through heterogeneous integration, Sci. China-Phys. Mech. Astron. 64, 217331 (2021), https://doi.org/10.1007/s11433-020-1596-5

Power electronics, processing over $50 \%$ of world's electric energy, enables very efficient electric energy conversion for a wide range of applications such as electric vehicles, data centers, autonomous driving, robotics and smart grids. The availability of low-cost, efficient, and reliable power semiconductor devices that can conduct high current, block high voltage, and switch at high frequencies are key to improving the performance of power electronics systems.

While most of today's power devices are made of silicon (Si), the power devices based on semiconductors possessing a wider bandgap than $\mathrm{Si}$, such as silicon carbide $(\mathrm{SiC})$ and gallium nitride $(\mathrm{GaN})$, have enabled numerous applications beyond the capabilities of Si. After three decades of relentless development, $\mathrm{SiC}$ and $\mathrm{GaN}$ devices have been commercialized. For example, high-performance, low-cost GaNon-Si device technologies have allowed a significant boost in power conversion efficiency and a reduction in system form factors [1], emerging vertical GaN-on-Si devices are also under development [2].

On the horizon is a new generation of semiconductors possessing even larger bandgaps than $\mathrm{GaN}$ and $\mathrm{SiC}$, i.e., the ultra-wide bandgap (UWBG) semiconductors. The major UWBG semiconductors include gallium oxide $\left(\mathrm{Ga}_{2} \mathrm{O}_{3}\right)$, aluminum nitride (AIN), and diamond. Power devices based on these materials promise higher theoretical performance than their $\mathrm{Si}, \mathrm{SiC}$, and $\mathrm{GaN}$ counterparts. Among various

*Corresponding author (email: yhzhang@vt.edu)
UWBG semiconductors, $\mathrm{Ga}_{2} \mathrm{O}_{3}$ is particularly promising owing to its controllable doping and the availability of large diameter wafers [3]. $\mathrm{Ga}_{2} \mathrm{O}_{3}$ devices have demonstrated high performance up to kilovolts classes.

Despite the initial success of $\mathrm{Ga}_{2} \mathrm{O}_{3}$ devices, they are faced with two fundamental material limitations. First, $\mathrm{Ga}_{2} \mathrm{O}_{3}$ has very low thermal conductivity ( $1 / 6$ of $\mathrm{Si}, 1 / 10$ of $\mathrm{GaN}$, and $1 / 20$ of $\mathrm{SiC}$ ), which limits its heat dissipation and power handing capabilities. Second, there still lacks shallow acceptors for efficient p-doping in $\mathrm{Ga}_{2} \mathrm{O}_{3}$. The absence of $\mathrm{Ga}_{2} \mathrm{O}_{3} \mathrm{PN}$ junctions hinders the adoption of many advanced voltage-blocking structures for the development of highvoltage power devices.

Two recent papers [4,5] published in Science China Physics, Mechanics \& Astronomy have showed good promise to overcome the above challenges through heterogeneously integrating $\mathrm{Ga}_{2} \mathrm{O}_{3}$ onto $\mathrm{Si}$ and $\mathrm{GaN}$. In ref. [4], the heterogeneous $\mathrm{Ga}_{2} \mathrm{O}_{3}$-on-Si substrate was demonstrated via an ioncutting process. Benefitting from the higher thermal conductivity of $\mathrm{Si}$ than that of $\mathrm{Ga}_{2} \mathrm{O}_{3}$, high-voltage (over $500 \mathrm{~V}$ ) enhancement-mode $\mathrm{Ga}_{2} \mathrm{O}_{3}$ metal-oxide-semiconductor fieldeffect transistors exhibited stable operation at high temperatures up to $200^{\circ} \mathrm{C}$. The demonstrated high-temperature voltage-blocking capabilities are among the best in all reported $\mathrm{Ga}_{2} \mathrm{O}_{3}$ transistors.

In ref. [5], $\mathrm{Ga}_{2} \mathrm{O}_{3}$ films are grown on the $\mathrm{GaN}$ substrate by metal organic chemical vapor deposition (MOCVD), the prevailing growth technique that enables the billion-dollar 
GaN optoelectronics and electronics markets. Such $\mathrm{Ga}_{2} \mathrm{O}_{3}$ films grown on the $\mathrm{GaN}$ substrate show significantly superior crystal quality, material homogeneity, and surface morphology compared with the $\mathrm{Ga}_{2} \mathrm{O}_{3}$ films grown on other foreign substrates. The fundamental understandings on the crystal and electronic structures of heterogeneous $\mathrm{GaN} / \mathrm{Ga}_{2} \mathrm{O}_{3}$ interfaces have also been acquired. These results pave the road for demonstrating heterogeneous $\mathrm{PN}$ junctions based on p-type $\mathrm{GaN}$ and n-type $\mathrm{Ga}_{2} \mathrm{O}_{3}$, which could be an enabling building block for future high-voltage $\mathrm{Ga}_{2} \mathrm{O}_{3}$ power devices.
1 K. J. Chen, O. Haberlen, A. Lidow, C. Tsai, T. Ueda, Y. Uemoto, and Y. Wu, IEEE Trans. Electron Devices 64, 779 (2017).

2 Y. Zhang, A. Dadgar, and T. Palacios, J. Phys. D-Appl. Phys. 51, 273001 (2018)

3 S. J. Pearton, J. Yang, P. H. Cary IV, F. Ren, J. Kim, M. J. Tadjer, and M. A. Mastro, Appl. Phys. Rev. 5, 011301 (2018).

4 Y. B. Wang, W. H. Xu, T. G. You, F. W. Mu, H. D. Hu, Y. Liu, H. Huang, T. Suga, G. Q. Han, X. Ou, and Y. Hao, Sci. China-Phys. Mech. Astron. 63, 277311 (2020).

5 Y. C. Zhang, Y. F. Li, Z. Z. Wang, R. Guo, S. R. Xu, C. Y. Liu, S. L. Zhao, J. C. Zhang, and Y. Hao, Sci. China-Phys. Mech. Astron. 63, 117311 (2020). 